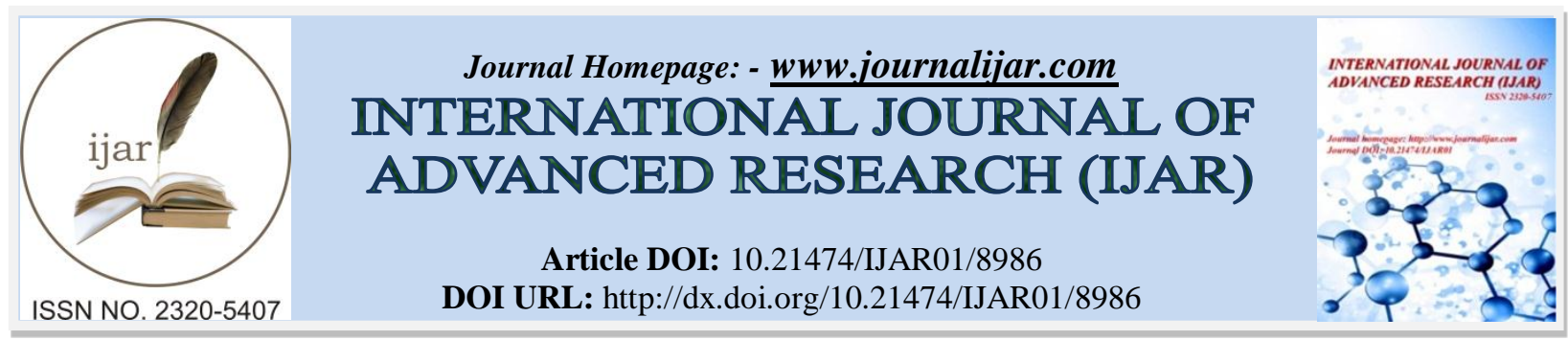

RESEARCH ARTICLE

\title{
PALATAL PLEOMORPHIC ADENOMA - A CASE REPORT.
}

Dev Kumar Garg ${ }^{1}$, Pooja Mahay ${ }^{2}$, Kanupriya Rathore ${ }^{3}$, Shaista Quraishi ${ }^{4}$ and Shahana Akhtar ${ }^{4}$.

1. Reader, Department of Oral and Maxillofacial Surgery, Maitri College of Dentistry and Research Center, Durg.

2. Reader, Department of Oral Medicine and Radiology, College of dental sciences, Bhavnagar.

3. Reader, Department of Peadiatric Dentistry, Jodhpur Dental College, Jodhpur.

4. Post Graduate Student, Department of Oral Medicine and Radiology, Maitri College of Dentistry and Research Center.

\section{Manuscript Info}

.........................

Manuscript History

Received: 25 February 2019

Final Accepted: 27 March 2019

Published: April 2019

Key words:-

Pleomorphic adenoma, minor salivary gland, palate.

\section{Abstract}

Minor salivary gland neoplasias are not age defined, as they can occur at any age. However, it is more likely for young patient to have benign tumors and older patients to have malignant neoplasms. The palatal tumors are more cellular and often grow rapidly than its major gland counterparts. The not- infrequent absence of connective tissue capsule or its incompleteness, infiltrate tumor growth, and a plane of ready cleavage make total excision of the tumor compulsory to minimize recurrence. We hereby are presenting a case of Pleomorphic adenoma of the minor salivary gland of palate. MRI was done for checking the extension of the lesion and its infiltration in nearby tissues. local excision was rendered as treatment for the lesion and there was no recurrence observed till 1 year after the surgery.

Copy Right, IJAR, 2019,. All rights reserved.

\section{Introduction:-}

Tumors are broadly classified into benign and malignant. Amongst the benign tumors of salivary gland, Pleomorphic adenoma is the most frequently encountered benign tumor in adults but rarely reported in children. Only $0.32-5 \%$ of all salivary gland tumors occur in children aged 16 years or younger ${ }^{1}$. The term Pleomorphic adenoma was suggested by WILLIS ${ }^{2}$ It is a slow growing tumor and it is also called as mixed tumor because, histologically it is characterized by a large variety of tissue consisting of epithelial cells arranged in a cord-like call pattern, together with areas of squamous differentiation or with plasmacytoid appearance. Myoepithelial cells are responsible for the production of abundant, extracellular matrix with chondroid, collagenous, mucoid and osseous stroma $^{3}$

In literature published it has been seen that the salivary gland neoplasm's, either benign or malignant, are usually present in major salivary glands, specially the parotid $(66-90 \%)^{4}$. Whenever they affect minor salivary glands, it is palate which is the mostly affected. Other intraoral sites include upper lips, buccal mucosa, tongue and gingiva. ${ }^{5}$ while taking gender into consideration, it was verified that generally, both benign and malignant types were more prevalent in women. Peak incidence relative to age showed variations, with concentrations at the third decade of life for benign tumors and the sixth decade for malignant tumors. ${ }^{6}$ 


\section{CASE REPORT}

A 15 year old boy came to the department of Pedodontics with the chief complaint of painless swelling in the right half of the palate ( Figure - 1). His medical history was non-contributing and there was no history of drug allergy and any surgery of head and neck. On detailed history, the swelling was present there for nearly $3 \frac{1}{2}$ year but grew rapidly in the past 3 months. Intraoral examination revealed a soft mass of $3.5 \mathrm{~cm}$ in greatest diameter at the right side of hard palate. The overlying mucosa was intact with no signs of inflammation. The lesion was rubbery in consistency and no tenderness on palpation was observed. Occlusal radiograph revealed no bony destruction. Incisional biopsy was performed on this patient. Microscopically, the lesion revealed encapsulated fibrous capsule with sheets, cords, islands and duct like structure of epithelial cells. Eosinophilic material was seen within the ductal structure and chondroid and myxoid areas were dispersed within the fibrocellular stroma ( Figure-2 ). The diagnosis was Pleomorphic adenoma. MRI showing the extension of lesion anteroposteriorly and buccolingualy ( Figure$3,4)$ The patient was treated by wide local excision of the affected area ( Figure- 5 ). The patient's postoperative course was uneventful. No recurrence was observed after a follow- up period of one years ( Figure - 6 )

\section{Discussion:-}

The proclination of salivary gland tumor is more towards malignancy in children than to be benign regardless of the site $^{7}$. The most common malignant salivary gland tumor is Mucoepidermoid carcinoma, while Pleomorphic adenoma is the benign counterpart ${ }^{1,7}$ In children and adolescents, pleomorphic adenoma of palate is rare. As reviewed by Byars et al. only 2 cases of palatal Pleomorphic adenoma were reported out of 470 cases of salivary gland tumor in patient of 18 years and below. Since then, there have been 13 more cases in the English literature ${ }^{\mathbf{8}}$. Daniels et al. reported 2 more such cases, bringing the total number of cases to 17 . The age of all the above said patients ranged from 5 to 17 years with the mean age of 10.75 years. The age of 10 of the 17 cases $(58.8 \%)$ was in first decade of life. The age of the patient in our case is slightly older than most previous reports; moreover the gender in our case is also not in accordance with previous reports since females slightly outnumber males by a ratio of 1.29:1.

The differential diagnoses include cysts of odontogenic and non-odontogenic nature, palatal abscess, soft tissue tumors and salivary gland tumors. Palatal abscess can be ruled out by clinical examination as there should be a source for the infection, which in most cases is a nonvital tooth or a localized periodontal defect, as both were not found. In addition, this patient showed no signs of inflammation. Both odontogenic and non-odontogenic cysts can be ruled out at the time of exploration into the mass since it did not demonstrate cystic nature. Palatal tissues contain components of soft tissue and harbor minor salivary gland tissues. As a result, soft tissue tumors such as fibroma, lipoma, neurofibroma, neurilemmoma as well as salivary gland tumors should also be considered in the differential diagnoses for this case. Lymphoma can also present with palatal swelling in children. The fact that this patient did not exhibit sign and symptom associated with malignant tumor such as ulcer, pain or paresthesia coupled with a rather slow development of the lesion over 2 years makes the differential diagnosis of lymphoma unlikely.

The treatment of palatal Pleomorphic adenoma in children is the same as in adults ${ }^{8}$. The treatment of choice for Pleomorphic adenoma in minor salivary gland is wide local excision with the removal of periosteum or bone if they are involved ${ }^{9}$. Simple enucleation of this tumor is believed to lead to high local recurrence rate and should be avoided ${ }^{10}$. Rupture of the capsule or tumor spillage is also believed to increase the risk of recurrence, so meticulous dissection is paramount. Pleomorphic adenoma generally does not recur after adequate surgical excision. Recurrence of palatal Pleomorphic adenoma in children following surgical treatment has been reported in 2 cases out of 17 cases from the English literature ${ }^{8}$.

\section{Conclusions:-}

Pleomorphic Adenoma of minor salivary gland is relatively rare and therefore its diagnosis requires a high index of suspicion. Its diverse histological and topographical property makes the tumor special. Successful treatment depends on the proper referral and biopsy aided diagnosis. The examining clinician and treating surgeon must be aware of its recurrence, longevity, and malignant potential if incorrectly diagnosed or treated. 


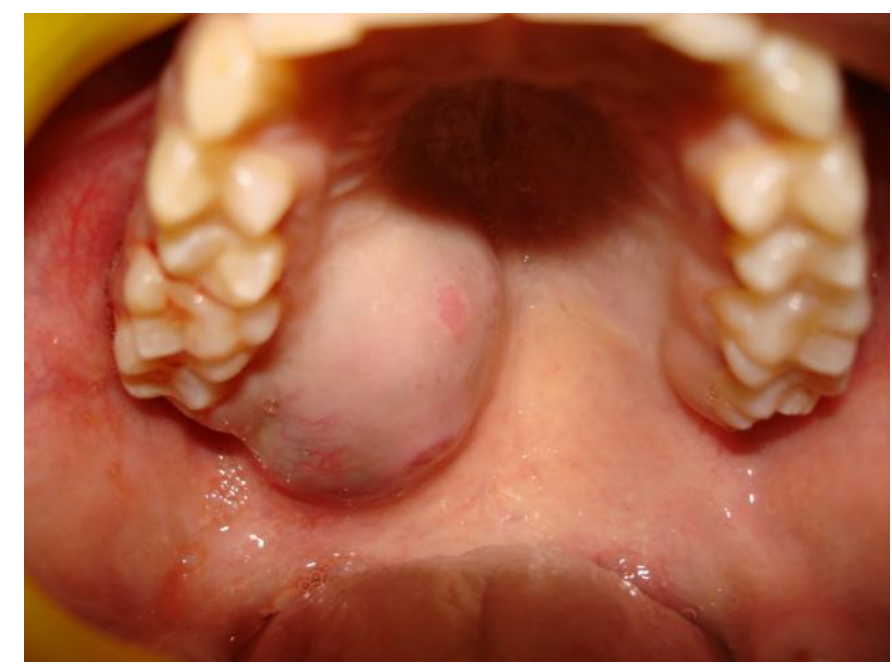

Figure - 1. Right palatal swelling measuring 3.5 X 2.5 ( approx )

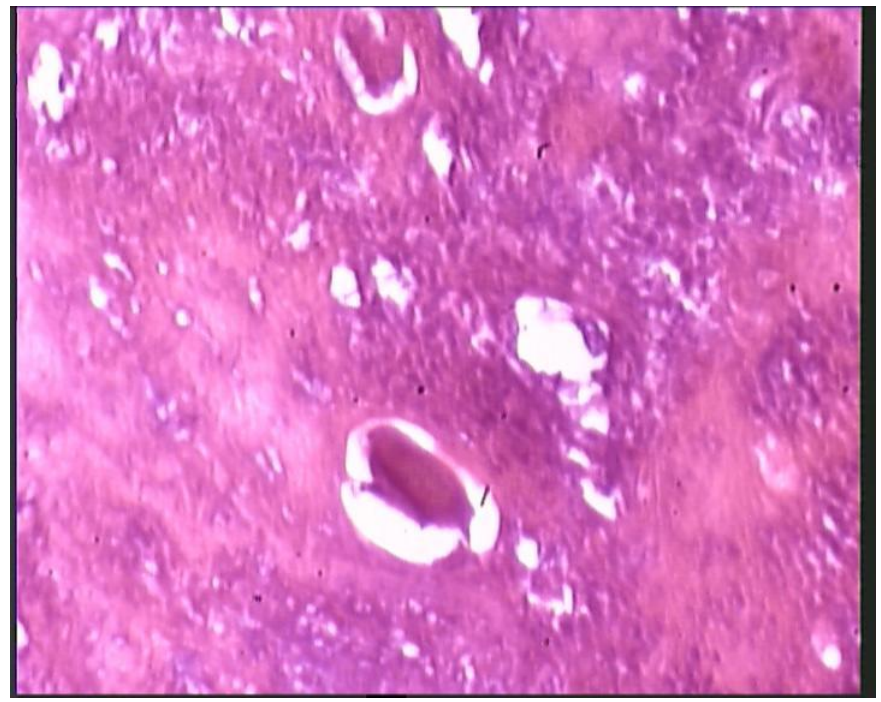

Figure - 2. Histopathological presentation of lesion

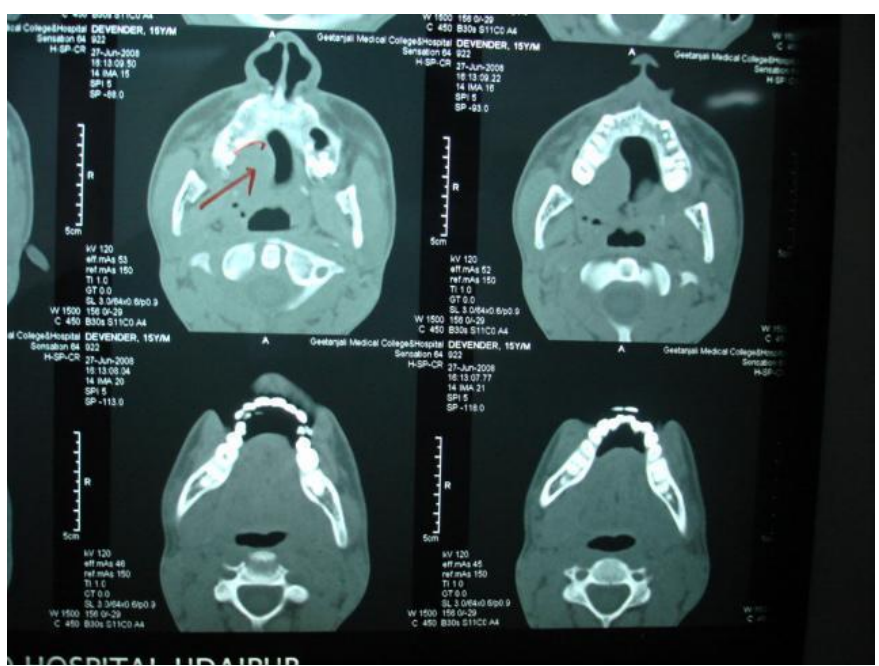

Figure - 3. MRI showing anteroposterior extension 


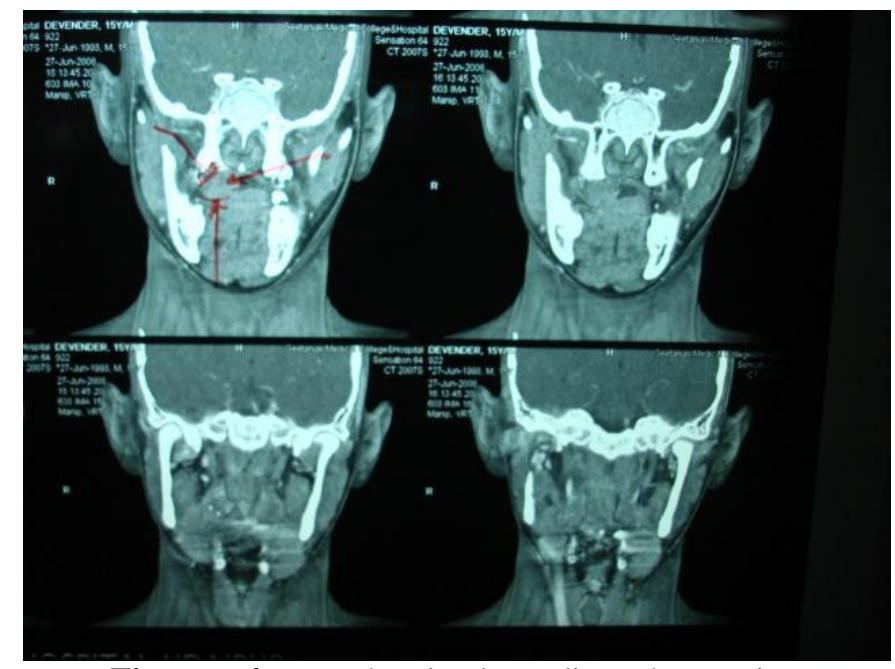

Figure -4 . MRI showing buccolingual extension

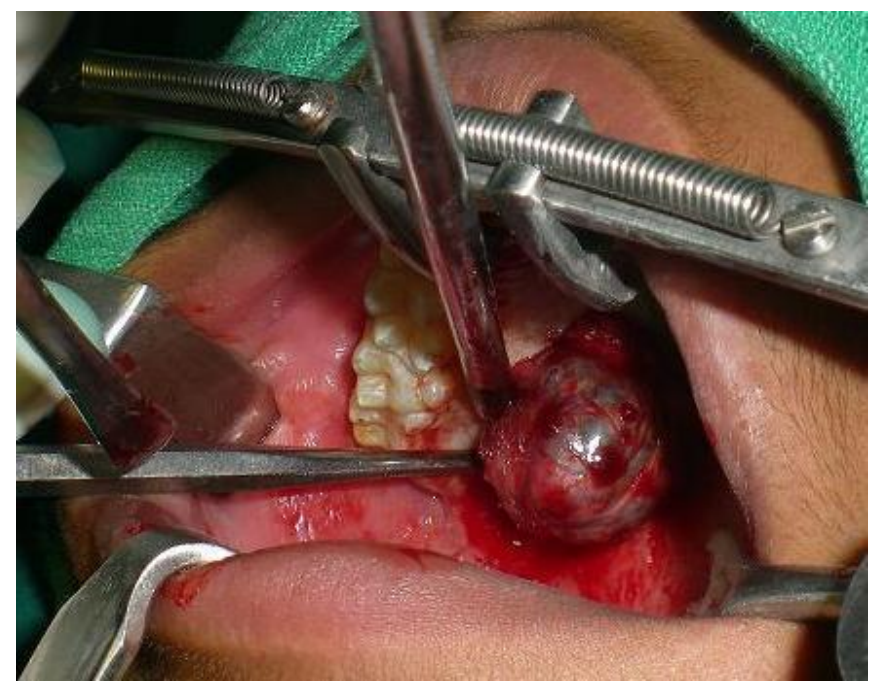

Figure -5 . Local excision of affected area

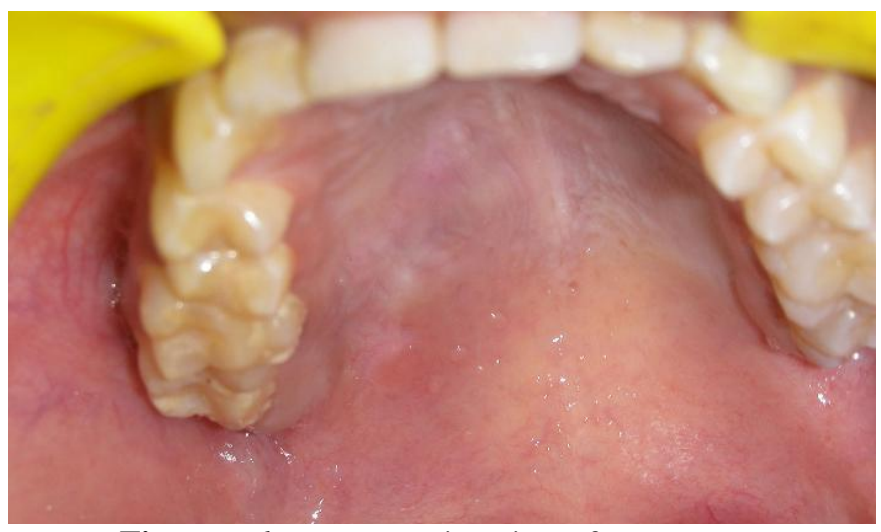

Figure - 6. Post operative view after one year 


\section{References:-}

1. Dhanuthai K, Banrai M, Limpanaputtajak S. A retrospective study of paediatric oral lesions from Thailand. Int J Paediatr Dent. 2007;17:248-53.

2. Califano J. and Eisele D.W. (1999); Benign salivary gland neoplasms. Otolaryngologic clinics of north America $32: 861-873$.

3. Seifert G,BrocheriouC,Cardesa A,Eveson JW(1990)WHO international histological classificationof tumors. Tentative histological classification of salivary gland tumors. Pathol Res Pract 186, 555-581.

4. Eveson JW, Cawson RA. Tumours of the minor (oropharyngeal) salivary glands: a demographic study of 336 cases. J Oral Pathol. 1985;14:500-9.

5. Chen YK, Lin LM, Lin CC, Yan YH. Palatal pleomorphic adenoma in a child with osteoid formation: report of case. ASDC J Dent Child. 1998;65:209-11.

6. Solange Souza Lima, Andréa Ferreira Soares, Rivadávio Fernandes Batista de Amorim, Roseana de Almeida Freitas:Rev Bras Otorrinolaringol. V.71, n.3, 335-40, may/jun. 2005

7. Bull PD. Salivary gland neoplasia in childhood. Int J Pediatr Otorhinolaryngol. 1999;49:S235-

8. Dhanuthai K, Sappayatosok K, Kongin K. Pleomorphic adenoma of the palate in a child: A case report. Med Oral Patol Oral Cir Bucal. 2009 Feb 1;14 (2):E73-5.

9. Nanda Kishore Sahoo, Mohan N. Rangan, Rajashekhar D. Gadad. Pleomorphic adenoma palate: Major tumor in a minor gland. Annals of Maxillofacial Surgery | July - December 2013 | Volume 3 | Issue 2:195-97

10. Ogata H, Ebihara S, Mukai K. Salivary gland neoplasms in children. Jpn J Clin Oncol. 1994;24:88-93. 